\title{
Implementation of a differentiated approach to the use of microwaves processing in the production of gelatin jellies
}

\author{
Ruslan Ikramov ${ }^{1, *}$, Liudmila Nilova $^{1}$, and Svetlana Malyutenkova ${ }^{1}$ \\ ${ }^{1}$ Peter the Great St. Petersburg Polytechnic University, 195251 Saint-Petersburg, Russia
}

\begin{abstract}
The market for jelly products based on natural raw materials is promising and is constantly expanding. For the production of gelatin jellies based on extracts from berry press residues, microwave technology was used, which made it possible to exclude the operation of swelling of gelatin for renaturation of proteins. The differentiated approach to the use of microwaves in the production of gelatin jellies influenced the technological parameters (time of heating the recipe mixture in a microwave oven; time of formation of the gelatin jellies structure upon cooling) and quality characteristics (plasticity, antioxidant activity). The absence of the gelatin swelling operation increased the microwave processing by $30-50 \%$ and the gelatin jellies structure formation time increased by $20-30 \%$, depending on the volume of the recipe mixture for processing and the weight of the finished product. Microwave processing increased the plasticity and antioxidant activity of gelatin jellies, which depended on the type of berry press residues used for extracts. The higher the antioxidant activity values (DPPH \& FRAP) of gelatin jellies were, the more their deformation values decreased. Gelatin jellies based on extract from blueberry press residues had the highest antioxidant activity and the lowest deformation values, while retaining their shape.
\end{abstract}

\section{Introduction}

Jelly and other jelly products (jelly candy, jelly cup, gummies) are a type of confectionery made from sugar syrups of fruit juices, fruit purees or water solutions of food additives (dyes, flavourings) and a gelling agent. In recent years, in order to increase their nutritional value, antioxidant properties and the formation of organoleptic indicators, it has been proposed to use products of processing plant raw materials instead of food additives [1-4]. The market for jelly products based on natural raw materials is promising and is constantly expanding $[2,5]$.

The quality of jelly and jelly products is influenced by the type and amount of gelling agents in the formulation. As gelling agents, both gelatin and plant structure-forming agents are used - pectin, agar, carrageenan and modified starches $[4,6]$. Kreungngem \& Chaikham [6] selected the formulation of jelly products with $3 \%$ potato flour, which provided the elastic-viscous properties of the gel, but gave a darker colour to the products. A

\footnotetext{
*Corresponding author: ruslan_ikramov@mail.ru
} 
combination of several gelling agents is possible. Leelawalt et al. [4] have shown that using tapioca starch at $1 \%$ forms a jelly structure while using $2.5 \%$ gelatin and $2 \%$ modified starch. To ensure the elasticity of jelly candy based on soursop (Annona muricata L.), various gelling agents can be used: $14 \%$ gelatin, $0.4 \%$ pectin, or $12 \%$ malt [7]. In the production of sugar-free jelly, to ensure the absence of syneresis, it is recommended to use a combination of xanthan gum and locust bean gum [8].

The traditional technology for the production of jelly products provides for hightemperature processing of the prepared mixture and the formation of a structure when it cools. As a result of heat treatment in jelly products, the content of biological active substances, antioxidants decreases [9-13]. Cunha et al. [10] found that heating the recipe mixture and boiling it for 45 minutes in the production of the curriola jelly led to significant losses, first of all, phenolic acids 2-3 times, vitamin C by $16.6 \%$. As a result, ABTS values decreased by $2.4 \%$, DPPH - by $6 \%$. In the production of jelly products from frozen semifinished products, the antioxidant activity (AOA) can decrease by $45 \%$ in jelly products from the pulp of grapes, pears, by $50 \%$ from the pulp of apples, and from the pulp of guava and strawberries, losses do not exceed $10 \%$. Storing frozen convenience foods for 90 days at minus $15^{\circ} \mathrm{C}$ did not change the loss of antioxidants [14].

Jelly candies made by two different mixing techniques (cold and hot). With hot technology, the prepared mixture is heated at a temperature of $125^{\circ} \mathrm{C}$; with cold technology, this operation is absent. After molding the prepared mixture, jelly candies are dried at $35^{\circ} \mathrm{C}$ for 72 hours. Cold-set jellies with strawberry juice showed about 3.3 times more phenolic compounds and 1.22 times more acid ascorbic content than pectin jellies with insignificant losses of anthocyanins [9]. Cold technologies allow replacing sugar with honey while preserving its biological activity, enriching foods with probiotics, and developing a range of products for children $[2,15]$. But such jelly products can be produced on the basis of vegetable semi-finished products with a high dry matter content. Gelatin jellies with a low solids content cannot be obtained using cold technology.

Microwave processing can become an alternative to conventional heating in the production of jelly [16]. Microwave processing enhances heat and mass transfer processes and more efficient heat transfer in the food matrix, resulting in higher quality products. Microwave processing is used to obtain extracts with a more efficient preservation of biologically active substances [17-19]. Microwave extraction allows you to increase the yield of individual antioxidants in the extract. Wei et al. [19] found that with a microwave power of $600 \mathrm{~W}$, an extraction time of $6 \mathrm{~min}$, a liquid to material ratio of $10: 1 \mathrm{ml} / \mathrm{g}$, and an extraction temperature of $85^{\circ} \mathrm{C}$, the maximum yield of polysaccharides and antioxidants from sea buckthorn berries can be achieved. Depending on the goals set, the microwave power and exposure time, voltage, at which drying and disinfection of the product is ensured, are selected [20-23]. Combined processing of microwave-infrared heating of plant raw materials leads to a sharp reduction in pathogenic microflora [22]. Microwave processing can become an alternative to thermal heating and boiling of a prepared mixture of components in the water solution for the production of jelly. Microwave processing allows you to heat a product of any volume in a consumer container.

The aim of this work is to modify the gelatin jellies microwave technology depending on the renaturation of proteins and the sequence of technological operations .

\section{Materials and methods}

Gelatin jellies were obtained on the basis of water extracts in the ratio: for cranberries 1.5: 10, for lingonberries 1.5: 10, for bilberries 1:10, for blueberries $1: 10$, as the sources of antioxidants [24, 25]. A microwave (magnetron power $800 \mathrm{~W}$, frequency $2450 \mathrm{MHz}$ ) was used to maximize the transfer of antioxidants from berry press residues to the extract. 


\subsection{Technology of gelatin jellies}

The recipe mix for the production of gelatin jellies included: extracts from berry press residues; gelatin 3 wt.\% (grade P-11, produced by LLC 'Russian Grocery Company', Russia; sugar $2.5 \mathrm{wt} \%$, for products based on cranberry and lingonberry extracts. All components were mixed. If necessary, the mixture was kept for 40 minutes to swell the gelatine. The recipe mixture was heated in a microwave oven (magnetron power $800 \mathrm{~W}$, frequency $2450 \mathrm{MHz}$ ) with or without preliminary swelling of gelatin. The duration of microwave processing varied depending on the presence or absence of the operation of swelling of gelatin and the volume of the prepared mixture, which was poured into molds up to or after microwave processing. The basic technology included a mixture volume of $100 \mathrm{ml}$, holding for 40 minutes, heating in a microwave oven for 60 seconds, cooling, pouring into molds and structuring at a temperature of $+4^{\circ} \mathrm{C}$ [16]. Gelatin jellies were used as a control. obtained by traditional technology with swelling of gelatin and bringing the prepared mixture to a boil on electric stove.

\subsection{Methods}

The strength of the 'Bloom strength' gelatin jellies was determined with the use of 'ST-2 Structometer', manufactured by Quality Laboratory LLC, Russia. This method is based on measuring penetration force by the Bloom indenter, when it penetrates the prepared jelly sample to the depth of $4 \mathrm{~mm}$ (at the penetration speed of $1.0 \mathrm{~mm} \mathrm{~s}^{-1}$, and the touch force of $7 \mathrm{~g})$.

Determination of AOA was carried out by two methods: by their reaction to the DPPHradical, by FRAP method.

A determination of AOA was carried out by use of the Glavind method [26]. Gelatin jellies were ground and extracted with $50 \%$ ethanol solution. A total of $0.2 \mathrm{~g}$ of the jellies was added to $2 \mathrm{ml}$ of DPPH solution. The resulting solution was incubated in the dark for five minutes, after which the absorbance levels of the resulting solution were measured at a wavelength of $517 \mathrm{~nm}$ using a SHIMADZU 1240 spectrophotometer ('SHIMADZU', Japan). The AOA was determined according to the calibration curve and expressed in terms of ascorbic acid (AC).

Determination of the AOA (chelating ability) using the FRAP method [26]. This method is based on the ability of ferric chloride (III) to oxidize antioxidants. During the process, ferric chloride (III) is reduced to ferric chloride (II), the amount of which is determined by the color intensity when $o$-phenanthroline is added to it. gelatin jellies were crushed and extracted with the use of the $50 \%$ ethanol. $0.2 \mathrm{ml}$ of the $25 \mathrm{mM}$ solution of $o$ phenanthroline, $2.4 \mathrm{ml}$ of the $96 \%$ ethanol and $0.2 \mathrm{ml}$ of the $12.3 \mathrm{mM} \mathrm{FeCl}_{3}$ solution (added drop by drop) were added to the extract. After stirring, the mixture was kept in a dark place for 10 minutes. The reaction was stopped by adding $1 \mathrm{ml}$ of the $0.4 \mathrm{M} \mathrm{HCl}$ solution. The control sample consisted of the original products to which $0.2 \mathrm{ml}$ of the 25 $\mathrm{mM} o$-phenanthroline solution, $2.6 \mathrm{ml}$ of the $96 \%$ ethanol, $0.2 \mathrm{ml}$ of the $12.3 \mathrm{mM} \mathrm{FeCl}_{3}$ solution, and $1 \mathrm{ml}$ of the $0.4 \mathrm{M} \mathrm{HCl}$ solution were added. The light absorption of the gelatin jellies was measured against the solution of the $96 \%$ ethanol with the use of SHIMADZU 1240 spectrophotometer at the wavelength of $505 \mathrm{~nm}$. The specific amount of gelatin jellies light absorption was subtracted from the amount of light absorption of the control sample. The AOA was determined according to the calibration curve and expressed in terms of AC.

The research was made in triplicate. The reliability of the experimental data was evaluated by methods of mathematical statistics with the use of Microsoft Excel application for Windows 2010. All the results were expressed as means \pm standard deviation and the statistical significance was assessed by Student's t test. 


\section{Results and Discussion}

At the first stage, the effect of renaturation of gelatin proteins on the formation of the structure of gelatin jellies was studied. They were produced according to the basic technology with preliminary swelling of gelatin in berry press residues for renaturation of proteins and without preliminary swelling, pouring into molds after cooling. The traditional boiling process was used as a control. The formation of the gelatin jellies structure occurred after the mixture was cooled to room temperature and kept in a refrigerator at a temperature of $+(4 \pm 2)^{\circ} \mathrm{C}$. The type of extract, volume and technology influenced the duration of the formation of the structure of gelatin jellies. When using the traditional technology (control), the formation of the gelatin jellies structure in $12 \mathrm{ml}$ molds occurred in 50-60 minutes. holding in a refrigerating chamber, and with a volume of $100 \mathrm{ml}$ - for 90 minutes. The use of microwave in the production of gelatin jellies with pre-swelling of the gelatin increased the duration of structure formation by $21-30 \%$. The maximum duration of gelatin jellies based on blueberry extract was 75-80 minutes. The absence of swelling of gelatin before microwave-assisted slowed down the formation of the structure of gelatin jellies by almost 2 times. The holding time was 140-150 minutes for molded products, and for gelatin jellies with a volume of $100 \mathrm{ml}$ the holding time was $180-190 \mathrm{~min}$.

Gelatin jellies were easily removed from the molds, had a bright transparent color, characteristic of the extracts of the corresponding berry press residues, with a slight melting in the mouth. Gelatin jellies had a consistency ranging from firm (for conventional samples) to plastic (for microwave-assisted products) (Fig. 1).

Gelatin jellies obtained using traditional technology were distinguished by a denser structure, the formation of which was facilitated by the high speed of molecular movement due to the additional energy at the boiling point of the prepared recipe mixture. microwaveassisted reduced exposure time by volumetric heating, but provided less thermal energy. This resulted in a $5 \%$ decrease in the strength values of the gelatin jellies control sample. The absence of preliminary swelling of gelatin, which is necessary to restore the solvation properties of proteins when creating a spatial network in the structure of the product, further reduced the strength of the control gelatin jellies samples by $29 \%$.

When using extracts from berry press residues, the strength values decreased by $12-$ $23 \%$, depending on the type of berry press residues for extraction, as compared to the control. Moreover, this trend was typical for all production methods (traditional> microwave with gelatin swelling > microwave without gelatin swelling). This confirms that the formation of the structure of gelatin jellies based on extracts is associated with proteinpolyphenol interaction and cross-linking [27, 28]. The more the extracts contain anthocyanins and other polyphenols with a branched structure and the higher their molecular mobility [29], the more pronounced the plastic properties of gelatin jellies. The predominance of anthocyanins in the blueberry press residues extract resulted in the formation of a more plastic product with the lowest strength values.

The strength of gelatin jellies depended not only on the technology and the type of extract, but also on the presence of sugar in the recipe (Table 1). 


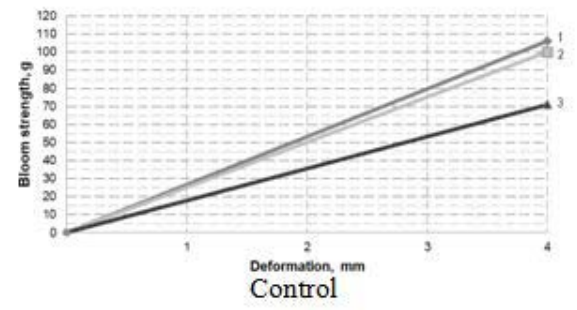

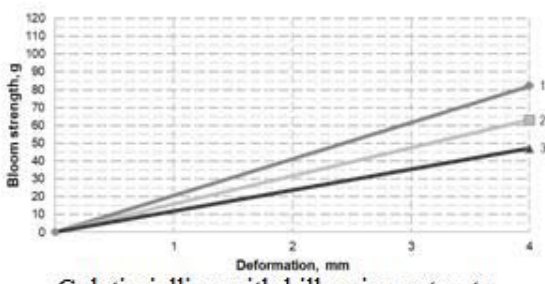

Gelatin jellies with bilberries extracts

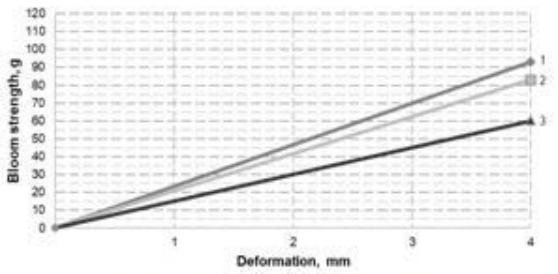

Gelatin jellies with cranberries extracts

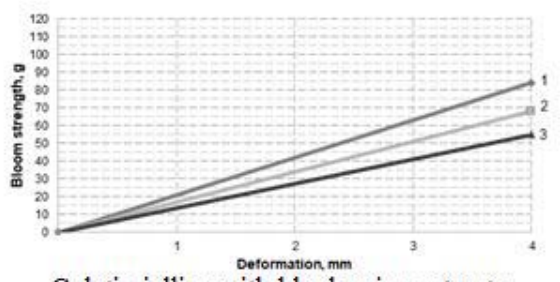

Gelatin jellies with blueberries extracts

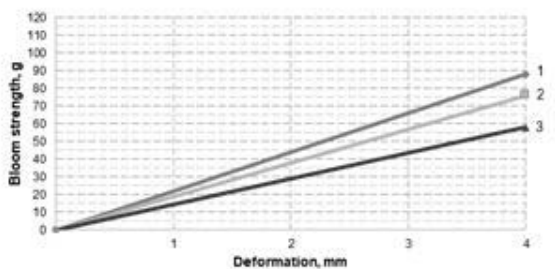

Gelatin jellies with lingonberries extracts

Fig. 1. Graphs of changes in the load force depending on the depth of the Blum indenter for sugarfree gelatin jellies, depending on the technology used: 1 - traditional; 2 - microwave with gelatin swelling; 3 - microwave without gelatin swelling.

Table 1. Influence of technology and type of berry press residues extracts on the strength of gelatin jellies, $g$.

\begin{tabular}{|c|c|c|c|c|c|c|}
\hline \multirow{3}{*}{$\begin{array}{l}\text { Gelatin } \\
\text { jellies }\end{array}$} & \multicolumn{6}{|c|}{ Technology } \\
\hline & \multicolumn{2}{|c|}{ traditional } & \multicolumn{2}{|c|}{$\begin{array}{l}\text { microwave with } \\
\text { gelatin swelling }\end{array}$} & \multicolumn{2}{|c|}{$\begin{array}{l}\text { microwave without } \\
\text { gelatin swelling }\end{array}$} \\
\hline & $\begin{array}{l}\text { without } \\
\text { sugar }\end{array}$ & $\begin{array}{l}\text { with } \\
\text { sugar }\end{array}$ & $\begin{array}{l}\text { without } \\
\text { sugar }\end{array}$ & $\begin{array}{l}\text { with } \\
\text { sugar }\end{array}$ & $\begin{array}{c}\text { without } \\
\text { sugar }\end{array}$ & $\begin{array}{c}\text { with } \\
\text { sugar }\end{array}$ \\
\hline Control & $106 \pm 2$ & $101 \pm 2$ & $100 \pm 3$ & $93 \pm 2$ & $71 \pm 3$ & $67 \pm 3$ \\
\hline $\begin{array}{l}\text { Bilberries } \\
\text { extracts }\end{array}$ & $82 \pm 2$ & $76 \pm 2$ & $63 \pm 3$ & $58 \pm 2$ & $47 \pm 2$ & $42 \pm 2$ \\
\hline $\begin{array}{l}\text { Blueberris } \\
\text { extracts }\end{array}$ & $84 \pm 2$ & $77 \pm 2$ & $68 \pm 2$ & $62 \pm 3$ & $55 \pm 2$ & $51 \pm 2$ \\
\hline $\begin{array}{l}\text { Cranberries } \\
\text { extracts }\end{array}$ & $93 \pm 2$ & $88 \pm 2$ & $83 \pm 3$ & $78 \pm 2$ & $60 \pm 3$ & $55 \pm 2$ \\
\hline $\begin{array}{l}\text { Lingonberris } \\
\text { extracts }\end{array}$ & $88 \pm 2$ & $82 \pm 3$ & $76 \pm 2$ & $70 \pm 3$ & $58 \pm 2$ & $55 \pm 2$ \\
\hline
\end{tabular}

Regardless of the technology for the production of gelatin jellies, the addition of sugar to their composition made it possible to obtain more plastic products. The values of plastic strength decreased when using the technology: microwave without gelatin swelling by 6$9 \%$; microwave with gelatin swelling - by $6-11 \%$, for traditional - by $5-8 \%$. When sucrose is dissolved in water, their energy of attraction exceeds the energy of hydrogen bonds of 
intermolecular interactions, due to which a structured system is formed. The use of sugar did not change the tendency of the effect of phenolic compounds on the plastic properties of gelatin jellies, reducing the values of plastic strength when using extracts of berry press residues, which formed a series: bilberry $<$ blueberry $<$ lingonberry $<$ cranberry.

Extracts berry press residues formed the antioxidant properties of gelatin jellies, which depended on the technology used (Fig. 2). Regardless of the method for determining the AOA, gelatin jellies obtained by traditional technology had the lowest values. The AOA of gelatin jellies obtained using microwave technology was higher than that of gelatin jellies obtained using traditional technology. DPPH values differed by $10-15 \%$, and FRAP - by 9 $17 \%$.
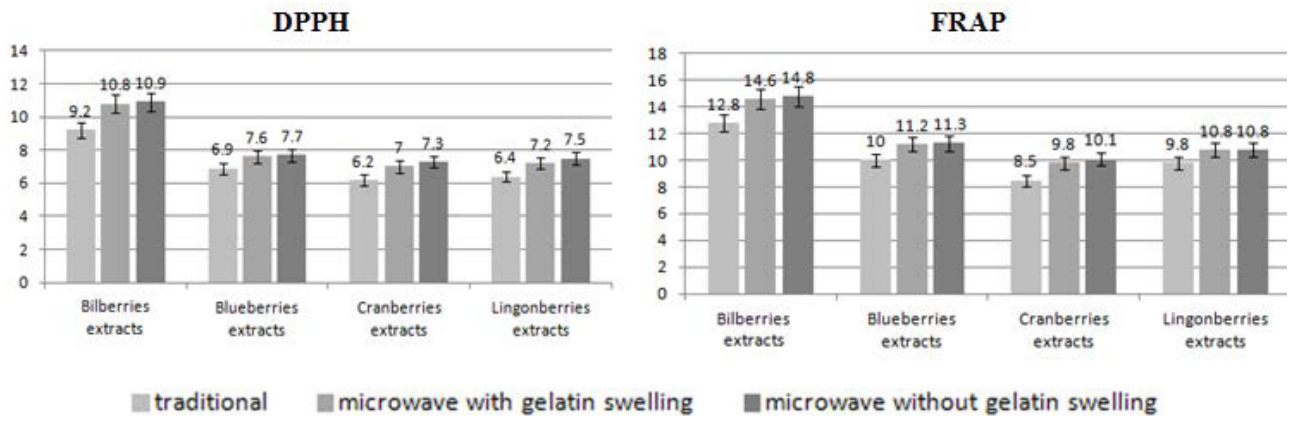

Fig. 2. Influence of technology on the antioxidant activity ( $\left.\mu \mathrm{g} \mathrm{AC} \mathrm{mg-}{ }^{1}\right)$ of gelatinous jellies based on the berry press residues.

All gelatin jellies contained antioxidants, as evidenced by the AOA values obtained by the two methods DPPH and FRAP. Fluctuations in the DPPH values of gelatin jellies

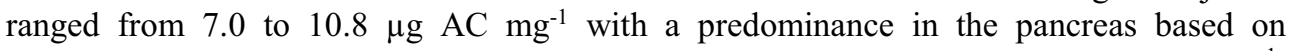
blueberry extracts. Fluctuations in FRAP values ranged from 9.5 to $14.6 \mu \mathrm{g} \mathrm{AC} \mathrm{mg}^{-1}$, which also prevailed in gelatin jellies based on extracts of bilberry press residues.

The use of preliminary swelling of gelatin or its absence before microwave processing of the prepared mixture did not significantly affect the DPPH and FRAP values of gelatin jellies. No statistically significant differences were found, although there was a tendency for greater retention of antioxidants in the absence of gelatin swelling.

In the absence of a gelatin pre-swelling operation, a longer microwave processing is probably needed to ensure protein renaturation and achieve the most approximate plasticity strength values of gelatin jellies. Therefore, an experiment was carried out in which the exposure time of the microwave was increased by $10-40 \mathrm{sec}$. compared to the originally used time of $60 \mathrm{sec}$. It was found that with microwave processing for $90 \mathrm{sec}$. gelatin jellies have the same plastic characteristics as gelatin jellies obtained with the preliminary swelling of gelatin. Thus, gelatin jellies based on 'extracts of various berries can be obtained without preliminary swelling of gelatin with exposure in an $800 \mathrm{~W}$ microwave oven for 90 seconds. or with preliminary swelling of gelatin and holding for 60 seconds, which forms identical plasticity and antioxidant properties.

Microwave processing can be carried out in forms of different volumes, both in the absence of preliminary swelling of gelatin, and with swelling. Pouring the prepared mixture before microwave processing into molds of a smaller volume to form the final mass and appearance of gelatin jellies should reduce the microwave processing time. We selected the duration of microwave processing with a power of $800 \mathrm{~W}$ when pouring the prepared mixture into silicone molds with a volume of $12 \mathrm{ml}$. The duration of microwave processing was varied from 10 to $30 \mathrm{sec}$. with an interval of $5 \mathrm{sec}$. The molds with the mixture were cooled and kept for $60 \mathrm{~min}$. at a temperature of $+(4 \pm 2)^{\circ} \mathrm{C}$. The control over the readiness 
of gelatin jellies was carried out according to the ability to be removed from the molds, as well as according to the plasticity properties, close to the previously determined characteristics (Table 1).

It was found that preliminary swelling of gelatin in extracts from berry press residues with subsequent filling into molds prior to microwave processing reduces the microwave processing time to $15 \mathrm{sec}$. In the absence of swelling, the microwave processing time is 30 sec. At the same time, gelatin jellies are easily removed from the forms, regardless of the type of extracts, and the plasticity characteristics are in the required range with deviations not exceeding 5 relative percent.

Thus, the use of microwave processing in the production of molded gelatin jellies is possible in several ways: with or without preliminary swelling of gelatin; with filling in molds before microwave processing or after (Fig. 3). For the formation of the same plasticity and antioxidant properties of molded gelatin jellies, it is necessary to change the duration of microwave processing, depending on the selected preparation method.

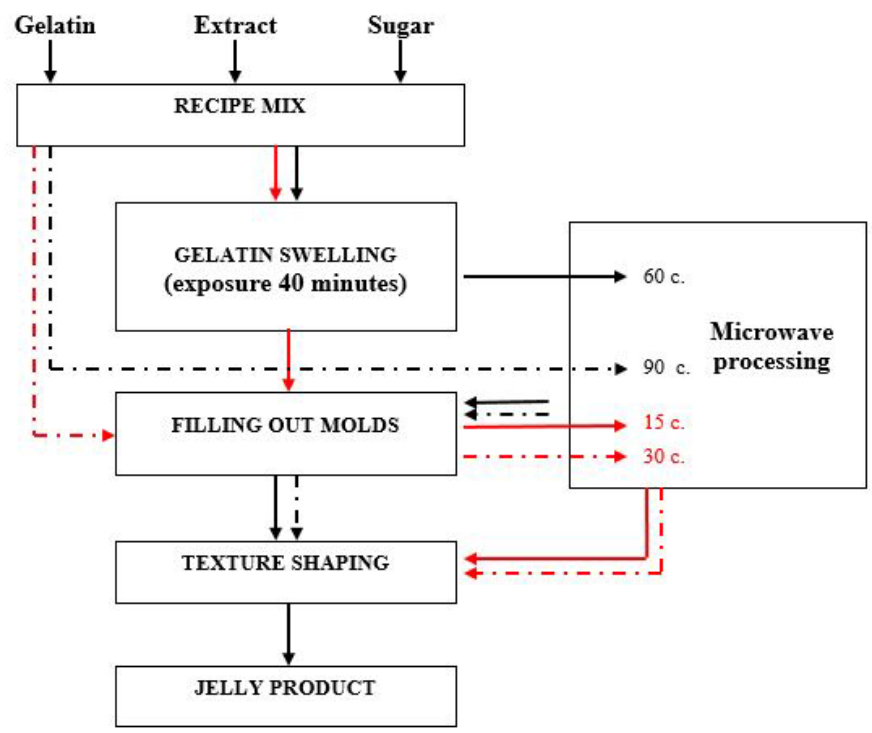

Fig. 3. Technology for the production of gelatin jellies based on extracts from various berry press residues using microwave processing.

\section{Conclusions}

The conducted experimental studies allow considering the use of microwave processing in the gelatin jellies production technology instead of heating on an electric heating device, which allows not to bring the prepared mixture of berry press residues and gelatin extracts to a boil, preserving antioxidants to a greater extent, forming gelatin jellies with more pronounced plasticity properties. The duration of microwave processing depends on the volume of the mixture prepared for heating. When using a prescription mixture with preliminary swelling of gelatin with a volume of $100 \mathrm{ml}$, microwave processing is carried out for 60 seconds, the absence of swelling increases the heating up to 90 seconds. Filling the prescription mixture into $12 \mathrm{ml}$ molds before microwave processing reduces the processing time to 30 seconds, and the pre-swollen mixture - to 15 seconds. All gelatin jellies exhibited AOA, with a predominance of extracts of bilberry press residues gelatin jellies, regardless of microwave processing. 


\section{References}

1. Ja. Ventura, F. Alarcyn-Aguilar, R. Roman-Ramos, E. Campos-Sepulveda, M.L. Reyes-Vega, V. Daniel Boone-Villa, E.I. Jasso-Villagymez, C.N. Aguilar, Food Chemistry 136, 109-115 DOI: http://dx.doi.org/10.1016/j.foodchem.2012.07.039

2. Jé.S. Miranda, B.V. Costa, I.V. de Oliveiraa, D.C.N. de Lima, E.M.F. Martinsa, B.R. de Castro Leite Júnior, W.C.A. do Nascimento Benevenuto, I.C. de Queiroz, R.R. da Silva, M.L. Martins, LWT - Food Science and Technology 126, 109275 (2020) DOI: https://doi.org/10.1016/j.lwt.2020.109275

3. N.S.S. Kumar, N. Sarbon, S. S. Rana, A.D. Chintagunta, S. Prathibha, S.K. Ingilala, S.P.Je. Kumar, B. S. Anvesh, V.R. Dirisala, AMB Express 11(1), 36 (2021) DOI: https://doi.org/10.1186/s13568-021-01194-9

4. B. Leelawalt, P. Permpoonchokkana, T. Jirapornsirikun, International Journal of Agricultural Technology 16(2), 297-308 (2020)

5. L. Nilova, S. Malyutenkova, E3S Web of Conferences 164, 09012 (2020) DOI: https://doi.org/10.1051/e3sconf /202016409012

6. D. Kreungngem, P. Chaikham, International Food Research Journal 23(4), 1474-1478 (2016)

7. T.T.Y. Nhi, N.D. Vu, N.N. Quyen, P.V. Thinh1, N.T.M. Tho, T.T. Truc, IOP Conference Series: Materials Science and Engineering 991, 012013 (2020) DOI: 10.1088/1757-899X/991/1/012013

8. H.A. Khouryieh, F.M. Aramouni, T.J. Herald, Journal of Food Quality 28, 179-190 (2005) DOI: 10.1111/j.1745-4557.2005.00014.x

9. M.H.M. de Avelar, G. de Castilho Queiroz, P. Efraim, Cleaner Engineering and Technology 1, 100005 (2020) DOI: https://doi.org/10.1016/j.clet.2020.100005

10. E.V. Alekseenko, V.Y. Chernykh, O.E. Bakumenko, IOP Conference Series: Earth and Environmental Science 640(5), 052007 (2021)DOI: 10.1088/1755-1315/640/5/052007

11. M. C. da Cunha, J. S/s Silva, H. H/ de Siqueira Ellas, E. E. Nunes Carvalho, E. V. de Barros Vilas Boas, Food Science and Technology 41(1), 96-104 (2021) DOI: https://doi.org/10.1590/fst.38519

12. M. Simonovik, S. Ostojic, D. Micic, B. Pejin, Natural Product Research 35(2), 337-341 (2021) DOI: 10.1080/14786419.2019.1622109

13. V.R. de Souza, P.A.P. Pereira, T.R. Teixeira, T.L.T. da Silva, R. Pio, F. Queiroz, International Journal of Food Science and Technology 50(7), 1658-1665 (2015) DOI: $10.1111 /$ ijfs. 12819

14. C.M.Je. Bof, R.C. Fontana, L.T. Piemolini-Barreto, I.G. Sandri, Braz. Arch. Biol. Technol. 55(1), 107-114 (2012) DOI: 10.1590/S1516-89132012000100014

15. C. Mutlua, S. A. Tontula, M. Erbaşa, LWT - Food Science and Technology 93, 499505 (2018) DOI: https://doi.org/10.1016/j.lwt.2018.03.064

16. L. Nilova, R. Ikramov, S. Malyutenkova, Agronomy Research 18(S3), 1829-1843 (2020) https://doi.org/10.15159/AR.20.044

17. R.G. Araujo, R.M. Rodríguez-Jasso, H.A. Ruíz, M. Govea-Salas, M. Pintado, C.N. Aguilar, Food and Bioproducts Processing 127, 152-161 (2021) DOI: 10.1016/j.fbp.2021.02.015

18. E.J. Davis, E. Spadoni Andreani, S. Karboune, Food and Bioproducts Technology 14(4), 634-649 (2021) DOI: 10.1007/s1 1947-021-02593-3 
19. E. Wei, E. Wei, R. Yang, H. Zhaoa, P. Wanga, S. Zhao, W. Zhai, Y. Zhang, H. Zhou, Journal of Biological Macromolecules 123, 280-290 (2019) DOI: 10.1016/j.ijbiomac.2018.11.074

20. R.L. Monteiro, N.N. Domschke, G. Tribuzi, J.T. Teleken, B.A.M. Carciofi, J.B. Laurindo, LWT 140, 110781 (2021) DOI: 10.1016/j.lwt.2020.110781

21. B. Shu, G. Wu, Z. Wang, J. Wang, F. Huang, L. Dong, R. Zhang, Y. Wang, D. Su, Journal of Food Measurement and Characterization 14(5), 2443-2452 (2020) DOI: 10.1007/s1 1694-020-00492-3

22. Sh.S. Shirkole, A.S. Mujumdar, R. Jayabalan, P.P. Sutar, Food Chemistry 338, 128012 (2021) DOI: 10.1016/j.foodchem.2020.128012

23. A. Garre, A. Acosta, J.D. Reverte-Orts, P.M. Periago, A. Díaz-Morcillo, A. Esnoz, J.L. Pedreño-Molina, P.S Fernández, Food Research International 137, 109640 (2020) DOI: $10.1016 /$ j.foodres.2020.109640

24. L. Nilova, S. Malyutenkova, R. Ikramov, IOP Conference Series: Earth and Environmental Science 337, 012025 (2019) doi:10.1088/1755-1315/337/1/012025

25. Yu.G. Bazarnova, O.B. Ivanchenko, Voprosy Pitaniia 85(5), 100-107 (2016)

26. V.V. Rogozhin, T.V. Rogozhina, Workshop on biochemistry of agricultural production (GIORD, St. Petersburg, 2015)

27. L.G. Gómez-Mascaraque, M. Martínez-Sanz, M.J. Fabra, A. López-Rubio, Food Hydrocolloids 90, 523-533 (2019)

28. J. Wu, Sh. Chen, Sh. Ge, J. Miao, J. Li, Q. Zhang, Food Hydrocolloids 32, 42-51 (2013) DOI: 10.1016/j.foodhyd.2012.11.029

29. I. Choi, S.E. Lee, Y. Chang, M. Lacroix, J. Han, LWT - Food Science and Technology 93, 427-433 (2018) DOI: 10.1016/j.lwt.2018.03.065

30. M. Ji, J. Wu, X. Sun, X. Guo, W. Zhu, Q. Li, X. Shi, Y. Tian, S.Wang, LWT 135, 110103 (2021) DOI: 10.1016/j.lwt.2020.110103 